\title{
Plasma metals as potential biomarkers in dementia: a case- control study in patients with sporadic Alzheimer's disease
}

\author{
Jingshu Xu $(\mathbb{D} \cdot$ Stephanie J. Church $\cdot$ Stefano Patassini $\cdot$ Paul Begley $\cdot$ \\ Katherine A. B. Kellett • Emma R. L. C. Vardy • Richard D. Unwin • \\ Nigel M. Hooper • Garth J. S. Cooper
}

Received: 11 December 2017 / Accepted: 26 February 2018/Published online: 7 March 2018

(C) The Author(s) 2018. This article is an open access publication

\begin{abstract}
Sporadic Alzheimer's disease (AD) is a neurodegenerative disorder that causes the most prevalent form of age-related dementia but its pathogenesis remains obscure. Altered regulation of metals, particularly pan-cerebral copper deficiency, and more regionally-localized perturbation of other metals, are prominent in AD brain although data on how these CNS perturbations are reflected in the peripheral bloodstream are inconsistent to date. To assess the potential use of metal dysregulation to generate biomarkers in $\mathrm{AD}$, we performed a case-control study of seven essential metals and selenium, measured by inductively coupled plasma massspectrometry, in samples from $\mathrm{AD}$ and matched control cases. Metals were sodium, potassium, calcium, magnesium, iron, zinc, and copper. In the whole study-group and in female participants, plasma metal levels did not
\end{abstract}

Jingshu Xu and Stephanie J. Church have contributed equally to this work.

J. Xu · S. J. Church · S. Patassini · P. Begley .

R. D. Unwin · G. J. S. Cooper

Centre for Advanced Discovery and Experimental

Therapeutics (CADET), Division of Cardiovascular

Sciences, School of Medical Sciences, Faculty of Biology,

Medicine and Health, The University of Manchester,

Manchester, UK

J. Xu · S. J. Church · S. Patassini · P. Begley ·

R. D. Unwin - G. J. S. Cooper

Central Manchester University Hospitals NHS Foundation

Trust, Manchester Academic Health Science Centre,

Manchester, UK differ between cases and controls. In males by contrast, there was moderate evidence that zinc levels trended towards increase in $\mathrm{AD}[10.8(10.2-11.5)] \mu \mathrm{mol} / \mathrm{L}$, mean $( \pm 95 \% \mathrm{CI} ; P=0.021)$ compared with controls $[10.2$ (9.6-10.4)]. Thus alterations in plasma zinc levels differed between genders in $\mathrm{AD}$. In correlational analysis, there was evidence for an increased number of 'strong' metal co-regulations in $\mathrm{AD}$ cases and differential comodulations of metal pairs: copper-sodium $\left(R_{\text {control- }}\right.$ $\left.=-0.03, R_{\mathrm{AD}}=0.65 ; P=0.009\right)$, and copper-calcium $\left(R_{\text {control }}=-0.01, R_{\mathrm{AD}}=0.65 ; P=0.01\right)$ were significant in $\mathrm{AD}$ males, potentially consistent with reported evidence for dysregulation of copper in severely damaged brain regions in $\mathrm{AD}$. In conclusion, our data suggest that the measurement of metals co-regulation in plasma may provide a useful representation of those metal perturbations taking place in the $\mathrm{AD}$ brain and therefore might be useful as plasma-based biomarkers.

\footnotetext{
K. A. B. Kellett · N. M. Hooper

Division of Neuroscience and Experimental Psychology,

School of Biological Sciences, Faculty of Biology,

Medicine and Health, The University of Manchester,

Manchester Academic Health Science Centre,

Manchester, UK

E. R. L. C. Vardy

Salford Royal NHS Foundation Trust, Manchester

Academic Health Science Centre, Salford, UK
} 


\section{Graphical Abstract}

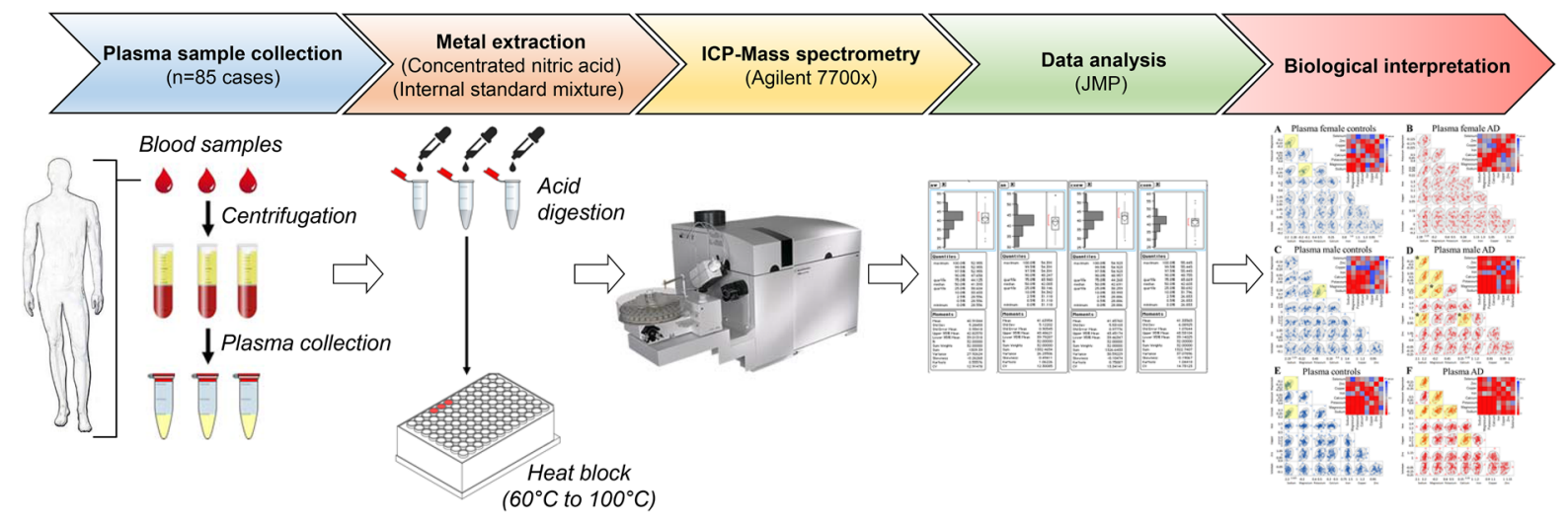

Keywords Alzheimer's disease - Dementia · Neurodegeneration $\cdot$ Human plasma $\cdot$ Metal biomarker · Plasma-zinc levels

$\begin{array}{ll}\text { Abbreviations } \\ \text { A } \beta & \text { Amyloid-beta } \\ \text { AD } & \text { Alzheimer's disease } \\ \text { APP } & \text { Amyloid precursor protein } \\ \text { BBB } & \text { Blood-brain barrier } \\ \text { CI } & \text { Confidence interval } \\ \text { FPG } & \text { Fasting plasma glucose } \\ \text { HbA1c } & \text { Hemoglobin A1c } \\ \text { ICP- } & \text { Inductively-coupled-plasma mass } \\ \text { MS } & \text { spectrometry } \\ \text { LC- } & \text { Liquid-chromatography mass-spectrometry } \\ \text { MS } & \\ \text { MMSE } & \text { Mini-mental state examination } \\ \text { NFT } & \text { Neurofibrillary tangle } \\ \text { NIST } & \text { National institute of standards and } \\ & \text { technology } \\ \text { ROS } & \text { Reactive oxygen species } \\ \text { SRM } & \text { Standard reference material }\end{array}$

G. J. S. Cooper ( $\square)$

School of Biological Sciences and Maurice Wilkins Centre for Molecular Biodiscovery, Faculty of Science, University of Auckland, Auckland, New Zealand e-mail: garth.cooper@manchester.ac.uk

G. J. S. Cooper

Rm 3.08, Core Technology Facility, Division of Cardiovascular Sciences, Faculty of Biology, Medicine and Health, The University of Manchester, Grafton Street, Manchester M13 9NT, UK
T2D Type-2 diabetes

\section{Introduction}

Sporadic Alzheimer's disease (AD), which has no known genetic basis, is the predominant cause of agerelated dementia globally (Ferri et al. 2005). Dementia has been predicted to affect around 136 million of the world-wide population by 2050 (Prince et al. 2013) but at present there are no treatments with proven diseasemodifying efficacy (Citron 2010). Therefore, AD is the largest unmet medical need in neurology and the associated socio-economic burden on our healthcare system is already huge and expected to grow dramatically in the future.

Major neuropathological hallmarks of AD include the presence of amyloid- $\beta$ (A $\beta)$ plaques and neurofibrillary tangles (NFTs) formed from tau protein, and synaptic loss. Proposed underlying mechanisms for AD pathogenesis include changes in the molecular regulation of amyloid precursor protein (APP) metabolism, oxidative stress, impaired energetics, mitochondrial dysfunction, inflammation, membrane lipid dysregulation and neurotransmitter pathway disruption (Kaddurah-Daouk et al. 2013). Defective regulation of metal homeostasis is also believed to play a significant role in the pathogenesis of $\mathrm{AD}$, however, there is no therapy targeting metal homeostasis registered for the treatment of $\mathrm{AD}$ at present (Ayton et al. 2013; Bush 2013; Sastre et al. 2015; Squitti 2012).

The human brain is a highly oxidative organ that contains abundant antioxidants, which can counteract 
the detrimental actions of reactive oxygen species (ROS) produced during the reaction of redox-active metals and molecular oxygen (Smith et al. 2007). A $\beta$ peptide can reportedly generate ROS in the presence of certain transition metals (Huang et al. 1999, 2004; Smith et al. 2007), which not only affect the synthesis, degradation and clearance of $A \beta$ but also participate in the aggregation of both $A \beta$ and NFT in the brain (Adlard and Bush 2006; Sastre et al. 2015). Acting in reverse, there is some evidence that both APP and A $\beta$ might modulate brain-metal homoeostasis. Furthermore, as an integral component of many metalloenzymes, metals modulate the normal function of numerous enzymes, processes and pathways via catalysis (Roberts et al. 2012).

In the $\mathrm{AD}$ research community, there is common agreement that advancements towards an effective therapy are hampered by the absence of robust and sensitive biomarkers that are needed as diagnostic, prognostic, predictive and pharmacodynamic-pharmacokinetic measurements to rapidly take decisions in the clinic and to quickly monitor the efficacy of disease-modifying therapies in clinical trials (Fiandaca et al. 2014).

Recently, systematic screening of plasma metal levels by inductively-coupled-plasma mass-spectrometry (ICP-MS) revealed the presence of altered metal metabolism in medical conditions involving the CNS (Nahan et al. 2017). In addition, the authors suggested that plasma metals might represent a good biomarker to gather diagnostic information in CNS-associated disorders. Here, in order to establish useful and accessible biomarkers of AD status, we have chosen to monitor events that are likely linked to fundamental features of $\mathrm{AD}$ pathogenesis or mechanisms underlying neurodegeneration in $\mathrm{AD}$. As defects in metal homeostasis have been widely established as a major feature of $\mathrm{AD}$ pathogenesis, we investigated whether the aberrant metal metabolism reported in AD brain is also reflected in an easily accessible source such as plasma (Akatsu et al. 2012; Ramos et al. 2014; Sastre et al. 2015; Xu et al. 2017). Whether it is possible to detect any dysregulation in metal levels in the plasma of $\mathrm{AD}$ cases, who undergo brain-metal perturbations (Xu et al. 2017), is critical for determining whether measurements incorporating metal levels might serve as diagnostic, prognostic, progression and pharmacodynamic/pharmacokinetic biomarkers of $\mathrm{AD}$ in the future.
Hence, the concentrations of elements, including the metals sodium, $\mathrm{Na}$; magnesium, $\mathrm{Mg}$; potassium, $\mathrm{K}$; calcium, $\mathrm{Ca}$; iron, $\mathrm{Fe}$; copper, $\mathrm{Cu}$; and zinc, $\mathrm{Zn}$; and the metalloid selenium, Se were determined by ICPMS in plasma from 42 patients with $\mathrm{AD}$ and in 43 controls with no evidence of impaired memory or clinical evidence for neurological disorder.

\section{Materials and methods}

\section{Ethics}

We performed this case-control study under a protocol approved by the Leeds Teaching Hospitals NHS Trust Research Ethics Committee. All procedures accorded with the ethics committee guidelines with informed consent from all participants or families of patients as appropriate.

\section{Patient selection}

Patients and controls without cognitive impairment were respectively recruited (Vardy et al. 2009) through memory clinics in Leeds and Dewsbury (England) and the Leeds Family Health Services Authority day hospitals and elderly medicine outpatient clinics in the Leeds area. All were of European Caucasian background and gave written informed consent (consent from relatives of the AD-patients was provided, where appropriate). Diagnosis of probable $\mathrm{AD}$ was made in accordance with international diagnostic criteria (National Institute of Neurological and Communicative Disorders and Stroke-Alzheimer's Disease and Related Disorders Association Work Group: NINCDS-ADRDA) (McKhann et al. 1984). All participants underwent a standardised clinical evaluation: medical history, fasting plasma glucose (FPG) and HbA1c (a measure of chronic glycaemia), and cognitive function assessment by Mini-Mental State Examination (MMSE). AD samples were selected by excluding patients with diagnosed T1D or T2D (including those taking insulin). Samples were then selected from the whole-study population for whom required measurements (FPG, HbA1c) were available (Vardy et al. 2007). The resulting $42 \mathrm{AD}$-patients were then age- and gendermatched to 43 controls (Table 1). 
Sample digestion

Plasma samples of $50 \mu \mathrm{L}$ were digested in $2-\mathrm{mL}$ microcentrifuge tubes (Eppendorf) as described below. Detailed method descriptions are available (Xu et al. 2017). Reactions were performed in concentrated nitric acid (A509 Trace Metal Grade; Fisher, Loughborough, UK) to which had been added 5\% (v/v) Agilent Internal Standard mixture (51834681; Agilent Technologies, Cheadle, UK). This internally standardised acid was also used at appropriate dilutions to provide rinse and calibration solutions, at $2 \%(\mathrm{v} / \mathrm{v})$ final nitric acid concentration.

Calibration solutions were produced by appropriate dilutions of Environmental Calibration Standard (Agilent 5183-4688). Acid digestion was carried out using an 'open-vessel' method. The tube lids were punctured to prevent pressure build up, and $0.2 \mathrm{ml}$ standardcontaining nitric acid added. Tubes were then inserted into a "Dri-block" heater, which was initially at room temperature. In parallel, $50-\mu l$ aliquots of NIST SRM 1950 plasma (Standard Reference Material; National Institute of Standards and Technology, Gaithersburg, MD), were processed in the same way. Tubes with standard-containing acid but no sample were also processed in each batch to provide "digestion" blanks. Temperature was then set to $60{ }^{\circ} \mathrm{C}$ and the block switched on. After $30 \mathrm{~min}$, the set temperature was increased to $100{ }^{\circ} \mathrm{C}$, and digestion continued for a further $210 \mathrm{~min}$. After digestion, the tubes were allowed to cool overnight.

Aliquots of $100 \mu \mathrm{L}$ were taken from each digestion solution and added to 15-mL Falcon tubes (525-0629, VWR, Lutterworth, UK) containing $5 \mathrm{~mL}$ LC-MS grade water, to produce solutions for analysis at a final nitric acid concentration of $2 \%(\mathrm{v} / \mathrm{v})$.

Metal measurements

Tissue metal concentrations were measured using an Agilent $7700 \times$ ICP-MS spectrometer equipped with a MicroMist nebulizer (Glass Expansion, Melbourne, Australia) and a Scott double-pass spray chamber. Sample introduction was performed using an Agilent Integrated autosampler (I-AS) with helium as the collision gas. A multi-element method including all elements present in the calibration solution was applied, as previously reported by our group (Church et al. 2015; Xu et al. 2017). Calibration solutions were produced by appropriate dilutions of Environmental Calibration Standard (Agilent 5183-4688). An intermediate concentration from this calibration series was used throughout as a periodic quality control sample. Instrument and digestion blanks were also interspersed throughout the experiment and the detection limit for each element determined by comparison of calibration samples and blanks. Scandium was used as the internal standard for all elements except $\mathrm{Zn}$ and Se, where germanium was used. Two collision-cell gas modes were applied: all elements were analysed in helium mode $(5.0 \mathrm{ml} / \mathrm{min}$ helium $)$, except for Se which was analysed in high-energy helium mode $(10 \mathrm{ml} / \mathrm{min}$ helium). Germanium internal standard was analysed in both modes. Mode selection followed Agilent recommendations to minimise interference for measured elements by e.g. isobaric cluster ions. Integration times were: $0.1 \mathrm{~s}$ for $\mathrm{Na}, \mathrm{Mg}, \mathrm{K}$ and $\mathrm{Ca} ; 0.3 \mathrm{~s}$ for $\mathrm{Cu}$ and $\mathrm{Zn} ; 0.01 \mathrm{~s}$ for $\mathrm{Fe}$; and $3 \mathrm{~s}$ for Se. NIST SRM plasma samples were also analysed within this experiment to check for precision of our measurements when compared to the certified values.

\section{Statistical methods}

The analysis for case-control study group characteristics was performed using SPSS Statistics 22 (IBM). Distributions of variables were tested for skewness using the Kolmogorov-Smirnov Goodness-Of-Fit test, for $42 \mathrm{AD}$ participants and 43 matched controls (Table 1). Parametric data are presented as mean $\pm \mathrm{s}-$ tandard error of the mean (SEM), and non-parametric data as median (range). Comparisons between $\mathrm{AD}$ and control groups were performed using an IndependentSamples $t$ test for parametric, and the Mann-Whitney $U$ test for non-parametric data. Pearson's $\chi^{2}$ analysis was performed on categorical data.

ICP-MS data were exported to Microsoft Excel and log-transformed for statistical analysis. Means ( $\pm 95 \% \mathrm{CI}$ ) of the log-transformed data were calculated and the significance of between-group differences was examined by unpaired $t$-tests with Welch's correction to allow for unequal variances and sample sizes. Means $( \pm 95 \% \mathrm{CI}$ ) were back-transformed to reflect the actual concentrations of elements. Statistical calculations were performed using GraphPad v6.04 (Prism; La Jolla, CA). $P$ values of $<0.05$ have been considered significant, and those of $0.05 \leq \mathrm{P}<$ 0.10 have also been tabulated. For correlation 
Table 1 Characteristics of participants in this study

${ }^{\mathrm{a} H e m o g l o b i n} \mathrm{~A} 1 \mathrm{c}$

\begin{tabular}{llll}
\hline Characteristic & AD & Control & $P$ value \\
\hline Number & 42 & 43 & - \\
Male (\%) & 52.4 & 53.5 & $\mathrm{NS}$ \\
Age (years) & $78.2 \pm 1.3$ & $78.1 \pm 1.1$ & $\mathrm{NS}$ \\
MMSE score & $21(11-25)$ & $29(27-30)$ & $<0.001$ \\
ApoE4 allele-positive (\%) & 71.4 & 32.6 & $<0.001$ \\
Fasting plasma glucose (mmol/l) & $5.0(3.8-10.6)$ & $5.1(4.2-8.9)$ & $\mathrm{NS}$ \\
Serum HbA1c $^{\mathrm{a}}$ & $5.6(5.1-7.8)$ & $5.7(5.1-8.4)$ & $\mathrm{NS}$ \\
\hline
\end{tabular}

analyses, serial pairwise correlations were generated between the reported metal abundances ( $\log _{10}$ transformed) using the statistical software $\mathrm{JMP}^{\circledR}$ (Version 12.0.0; SAS Institute, Cary, NC). The correlations generated were visually depicted using scatter plot matrices and those considered as "strong" (Pearson coefficient $R>0.5 \quad($ or $<-0.5)$ and $P$ values $<0.001)$ were further investigated. The statistical significance of differences in correlation coefficients between strong correlations in controls and AD groups was determined by Fisher r-to-z transformation and resulting $P$ values $<0.05$ (two-tailed) were considered significant.

\section{Results and discussion}

In this study, we measured concentrations of seven essential metals and the metalloid, Se, in plasma samples from 42 cases with $\mathrm{AD}$ and 43 matched control participants (Table 1). We matched participants in this case-control study for gender and age (Table 1). Consistent with expectation, measured cognitive function (MMSE scores) was significantly lower in the $\mathrm{AD}$ group than controls whereas the ApoE4 allele was more prevalent. Levels of FPG and serum $\mathrm{HbA1c}$ were equivalent between groups. There was no evidence for elevated rates of undiagnosed T2D or impaired glucose tolerance (IGT)/impaired fasting glucose (IFG) in this group of British patients with sporadic AD (Table 1). Therefore, the current study compares plasma metal levels in $\mathrm{AD}$ cases representative of sporadic $\mathrm{AD}$ with appropriately matched controls.

We rigorously controlled the application of the ICP-MS methodology and have a high degree of confidence in the robustness of our data. For example, we included NIST SRM plasma samples in our study as previously described (Xu et al. 2017) and verified that measurements were within the $\pm 5 \%$ difference range compared to the certified values, indicating the precision of the methodology applied in this study.

We analysed the female and male datasets separately, and then combined them, in order to highlight possible effects of gender in control and AD participants (Table 2, Fig. 1). In the female patients, none of the eight measured elements differed in their plasma concentrations between the $\mathrm{AD}$ and control groups $(P=0.021$; Table 2$)$. However, in male patients, there was modest evidence that $\mathrm{Zn}$ trended towards increase in the $\mathrm{AD}$ group compared to the control group (Table 2). This might be consistent with previouslyreported elevations in levels of $\mathrm{Zn}$ in AD brain (Schrag et al. 2011), and possibly also with enrichment of $\mathrm{Zn}$ in and around amyloid plaques (Lovell et al. 1998). However, reports concerning elevations of $\mathrm{Zn}$ in AD brain are not uniform. For example, in a recent metallomic study, brain-Zn levels in AD were moderately elevated in only three of seven regions studied: entorhinal cortex, middle temporal gyrus, and cerebellum (Xu et al. 2017). By contrast, they were similar to control values in other regions known to contain high levels of amyloid plaques in AD. Thus, the relationship between bulk regional $\mathrm{Zn}$ concentrations and $\mathrm{Zn}$ in amyloid plaques is not entirely clear. Since multi-regional studies of brain metal content are sparse, it is difficult to reach firm conclusions concerning the occurrence or significance of elevated brain- $\mathrm{Zn}$ levels in $\mathrm{AD}$.

In addition, the observation of elevated serum- $\mathrm{Zn}$ levels in males but not females with $\mathrm{AD}$ is an intriguing finding. Some workers have suggested that altered $\mathrm{Zn}$ homeostasis could play a significant role in AD pathogenesis, since it can clearly interact with APP and A $\beta$, and reportedly participates in APP processing, and aggregation and clearance of $A \beta$ in the 
AD-brain. Data strongly support the enrichment of $\mathrm{Zn}$ in the core of $A \beta$ plaques, a process that has been suggested to disrupt $\mathrm{Zn}$ homeostasis in brain regions important for memory generation and vulnerable to AD pathogenesis (Craddock et al. 2012; Miller et al. 2006). However, we note that interventions aimed at ameliorating alterations in $\mathrm{Zn}$ homeostasis have no accepted role in the management of $\mathrm{AD}$ at the time of writing.

In our combined analyses that included separate analysis of data from both genders, none of the measured metals showed statistically significant between-group concentration differences (Table 2). Therefore, our results suggest that alterations in plasma metal levels in association with $\mathrm{AD}$ may be inconsistent between genders. In line with our
Fig. 1 Correlations between metal levels in the plasma of AD cases and controls. Scatter plots of metal abundance correlations are shown for each metal measured in control (blue) and AD (red) plasma in females (a, b), male (c, d) and combined sexes $(\mathbf{e}, \mathbf{f})$. Shown are $P$ values corresponding to each metal-pair, with correlations as a gradient colour in the heat map for each gender group. All the strong correlations $(R>0.5$ (or $<-0.5$ ) and $P$ values of $<0.001)$ are highlighted in yellow and, for each correlation, grey ellipsoids represent the $95 \%$ confidence interval. Note that the metal co-regulations were only perturbed in the male AD cases whereas values were unaffected in females or combined groupings. *Significantly different correlations (Fisher r-to-z transformation $P$ values $<0.05$ ) between control and $\mathrm{AD}$ participants in the male group. Legend: control males (blue triangles); control females (blue circles); AD males (blue circles); AD females (red circles). (Color figure online)

observations, a previous study concluded that metal levels are not consistently altered in plasma of $\mathrm{AD}$

Table 2 Plasma metal concentrations in groups of females, males and combined sexes

\begin{tabular}{|c|c|c|c|c|c|}
\hline Element (reference isotope) & Concentration unit & Groups & Control & $\mathrm{AD}$ & $P$ value \\
\hline \multirow[t]{3}{*}{$\mathrm{Na}\left({ }^{23} \mathrm{Na}\right)$} & \multirow[t]{3}{*}{$\mathrm{mmol} / \mathrm{L}$} & $\mathrm{F}$ & $170(166-175)$ & $167(164-169)$ & NS \\
\hline & & M & $160(158-162)$ & $162(156-167)$ & NS \\
\hline & & $\mathrm{F} \& \mathrm{M}$ & $165(162-167)$ & $164(161-167)$ & NS \\
\hline \multirow[t]{3}{*}{$\mathrm{Mg}\left({ }^{24} \mathrm{Mg}\right)$} & \multirow[t]{3}{*}{$\mathrm{mmol} / \mathrm{L}$} & $\mathrm{F}$ & $0.70(0.67-0.73)$ & $0.70(0.69-0.74)$ & NS \\
\hline & & M & $0.70(0.66-0.71)$ & $0.70(0.68-0.73)$ & NS \\
\hline & & $F \& M$ & $0.70(0.67-0.71)$ & $0.70(0.69-0.73)$ & NS \\
\hline \multirow[t]{3}{*}{$\mathrm{K}\left({ }^{39} \mathrm{~K}\right)$} & \multirow[t]{3}{*}{$\mathrm{mmol} / \mathrm{L}$} & $\mathrm{F}$ & $3.3(3.2-3.5)$ & $3.2(3.0-3.4)$ & NS \\
\hline & & M & $3.3(3.1-3.4)$ & $3.3(3.1-3.4)$ & NS \\
\hline & & $F \& M$ & $3.3(3.2-3.4)$ & $3.3(3.1-3.4)$ & NS \\
\hline \multirow[t]{3}{*}{$\mathrm{Ca}\left({ }^{44} \mathrm{Ca}\right)$} & \multirow[t]{3}{*}{$\mathrm{mmol} / \mathrm{L}$} & $\mathrm{F}$ & $1.9(1.8-1.9)$ & $1.8(1.8-1.9)$ & NS \\
\hline & & M & $1.7(1.6-1.7)$ & $1.8(1.7-1.8)$ & 0.087 \\
\hline & & $\mathrm{F} \& \mathrm{M}$ & $1.8(1.7-1.8)$ & $1.8(1.7-1.8)$ & NS \\
\hline \multirow[t]{3}{*}{$\mathrm{Fe}\left({ }^{56} \mathrm{Fe}\right)$} & \multirow[t]{3}{*}{$\mu \mathrm{mol} / \mathrm{L}$} & $\mathrm{F}$ & $17.6(14.5-21.3)$ & $17.8(16.3-19.5)$ & NS \\
\hline & & M & $20.1(16.9-24.1)$ & $18.4(16.7-20.4)$ & NS \\
\hline & & $F \& M$ & $18.9(16.6-21.5)$ & $18.1(17.0-19.4)$ & NS \\
\hline \multirow[t]{3}{*}{$\mathrm{Cu}\left({ }^{63} \mathrm{Cu}\right)$} & \multirow[t]{3}{*}{$\mu \mathrm{mol} / \mathrm{L}$} & $\mathrm{F}$ & $15.9(14.6-17.3)$ & $14.5(13.3-15.8)$ & NS \\
\hline & & M & $13.2(12.1-14.3)$ & $12.7(11.7-13.9)$ & NS \\
\hline & & $F \& M$ & $14.4(13.5-15.3)$ & $13.5(12.7-14.4)$ & NS \\
\hline \multirow[t]{3}{*}{$\mathrm{Zn}\left({ }^{66} \mathrm{Zn}\right)$} & \multirow[t]{3}{*}{$\mu \mathrm{mol} / \mathrm{L}$} & $\mathrm{F}$ & $10.2(9.8-10.7)$ & $10.5(9.5-11.6)$ & NS \\
\hline & & M & $10.0(9.6-10.4)$ & $10.8(10.2-11.5)$ & $0.021 *$ \\
\hline & & $F \& M$ & $10.1(9.8-10.4)$ & $10.7(10.1-11.2)$ & 0.075 \\
\hline \multirow[t]{3}{*}{$\mathrm{Se}\left({ }^{78} \mathrm{Se}\right)$} & \multirow[t]{3}{*}{$\mu \mathrm{mol} / \mathrm{L}$} & $\mathrm{F}$ & $0.90(0.84-0.98)$ & $1.00(0.89-1.05)$ & NS \\
\hline & & M & $0.90(0.86-1.01)$ & $0.90(0.81-0.95)$ & NS \\
\hline & & $F \& M$ & $0.90(0.87-0.97)$ & $0.90(0.86-0.97)$ & NS \\
\hline
\end{tabular}

Data are means $( \pm 95 \% \mathrm{CI}) ; P$ values for significance of between-group differences were calculated by applying Welch's modified $t$ tests to metal measurements from plasma samples from female patients $(\mathrm{F})$ [control $(\mathrm{n}=20)$ and $\mathrm{AD}(\mathrm{n}=19)]$, male patients (M) [control $(\mathrm{n}=23)$ and $\mathrm{AD}(\mathrm{n}=23)]$, and all patients combined $(\mathrm{F} \& \mathrm{M})$ [control $(\mathrm{n}=43)$ and $\mathrm{AD}(\mathrm{n}=42)]$

*Significant $(P$ values $<0.05)$ 
A

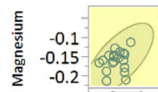

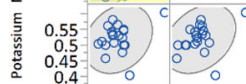

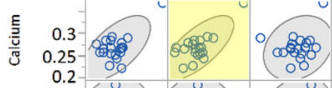

至 1.2.

$0.6-6$
1.25

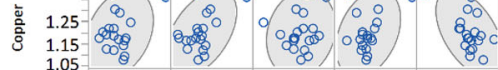

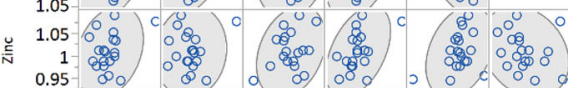

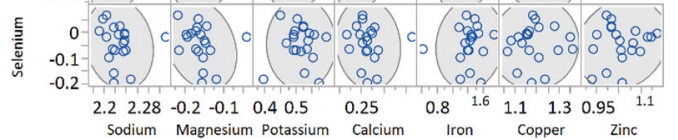

C

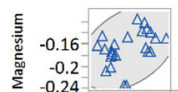

至 $0.24 \Delta \Delta \Delta \Delta \Delta$

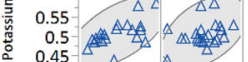

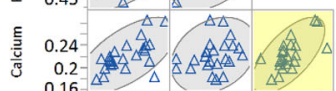
0.16

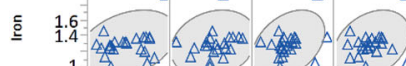

Plasma male controls

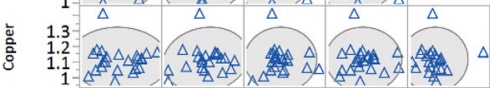

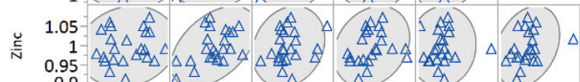

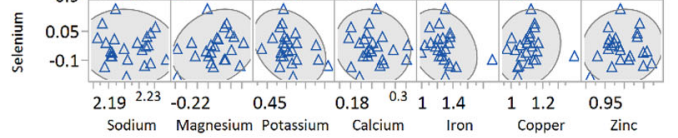

E

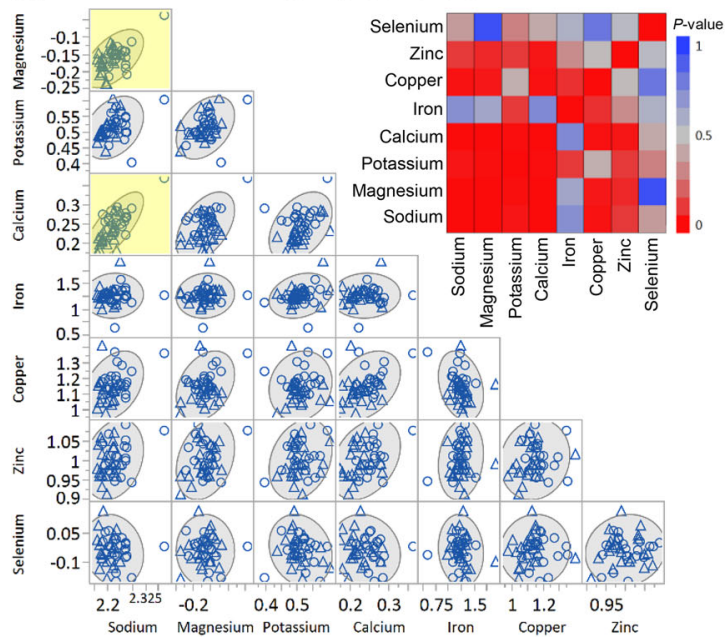

B

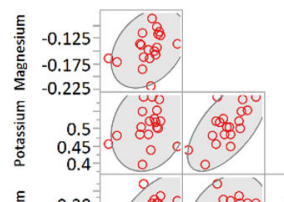

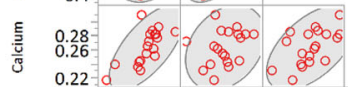

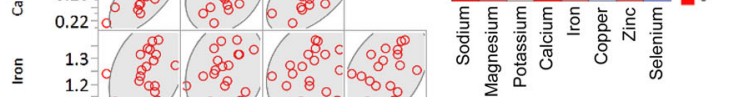

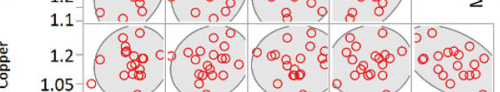

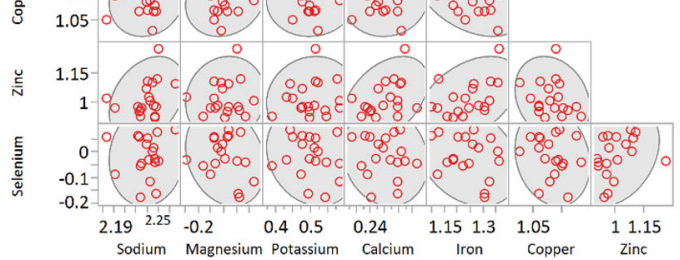

D

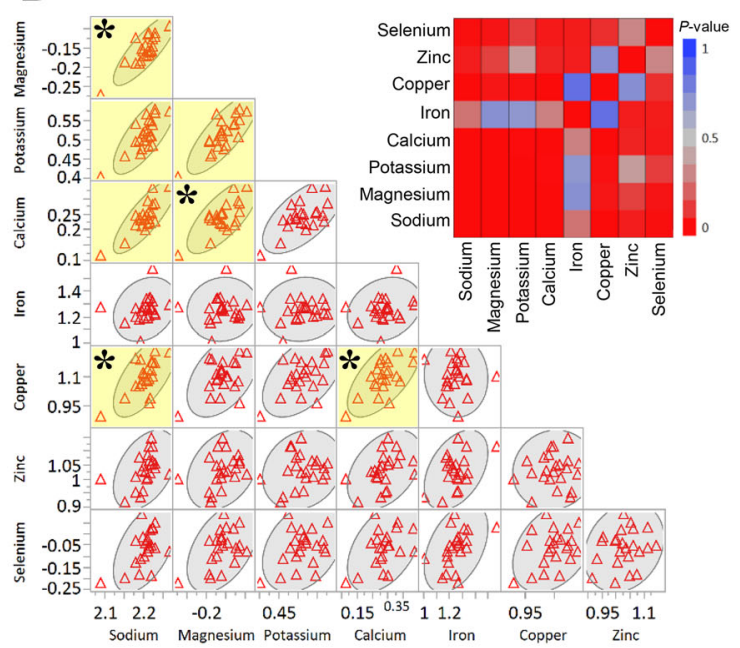

F

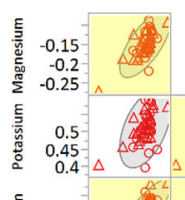

善 $\begin{aligned} & 0.25 \\ & 0.25\end{aligned}$

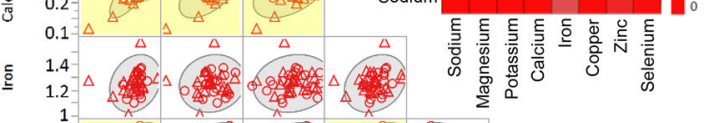

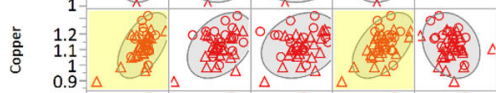

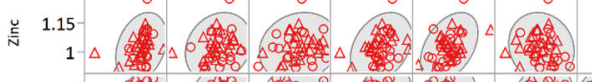

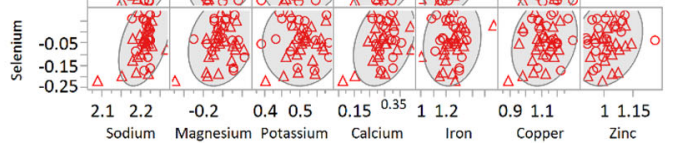


participants, except for an elevated abundance of mercury (Gerhardsson et al. 2008). Other studies have reported decreased plasma levels of $\mathrm{Mg}, \mathrm{Cu}, \mathrm{Zn}, \mathrm{Fe}$ and Se (Vural et al. 2010) and serum levels of Zn (Huang et al. 2013) in patients with AD compared with controls using different approaches, but the findings of our current study are not consistent with these prior reports, perhaps due to the minor differences of method employed. However, we would note that the evidence generated from our study is strongly supported by the methods employed and the use of the NIST SRM as a control to verify the efficacy of the digestion and metal recovery and measurements processes [for further data concerning the performance of our methods, see (Xu et al. 2017)].

We also performed an exploratory pairwise correlational analysis to ascertain how the measured metals might be differently co-regulated between controls and cases. Firstly, the number of strong correlations $(R>0.5$ (or $<-0.5)$ and $P$ values $<0.001$ ) was determined for each group (Table 3, Fig. 1). We observed a higher number of strong correlations in the all-AD group ( 18\% increase; Table 3$)$, a finding possibly consistent with a systemic alteration of metal co-regulation in these patients. Notably, when we divided the groups by gender, only the AD-male group showed an increase in strong correlations $(\sim 21.5 \%$ increase). In addition, in the male group there were significant changes between pairwise correlations in metal levels between the controls and cases. Significant differences included changes in the following metal-metal pairs: magnesium-sodium $\left(R_{\text {control- }}\right.$ $\left.=0.41, R_{\mathrm{AD}}=0.84 ; P=0.02\right)$; calcium-magnesium $\left(R_{\text {control }}=0.28, \quad R_{\mathrm{AD}}=0.73 ; \quad P=0.04\right) ; \quad$ coppersodium $\left(R_{\text {control }}=-0.03, R_{\mathrm{AD}}=0.65 ; P=0.009\right)$; and copper-calcium $\left(R_{\text {control }}=-0.02, R_{\mathrm{AD}}=0.65\right.$; $P=0.01)$. These copper-associated correlations were the most significant differences observed in AD-male participants when compared to controls (Fig. 1a-f).
Interestingly, in another study in patients with $\mathrm{AD}$, substantively elevated sodium levels were present in all three severely damaged brain regions assessed: hippocampus, entorhinal cortex, and middle temporal gyrus. Copper was markedly decreased in these regions as well, but also in four other brain regions studied (Xu et al. 2017). Therefore, there is some evidence for a copper-sodium interaction in the brain of patients with $\mathrm{AD}$, which may be related to the finding of a sodium-copper correlation in the plasma.

T2D has strong epidemiological ties with $\mathrm{AD}$, and $\mathrm{T} 2 \mathrm{D}$ is known to cause significant perturbations in the systemic homeostasis of numerous essential metals (Cooper et al. 2005). It was therefore important to eliminate it from both groups in the current study, to exclude any possible confounding effect from participants with known T2D or those with undiagnosed disease. We did this by history, and screening all potential participants for T2D using FPG and HbA1c measurements. This is a precaution that should be undertaken in future studies of systemic metal regulation in $\mathrm{AD}$, in order to avoid a possible confounding effect by untoward inclusion of patients with T2D, particularly given reports of increased prevalence of T2D in populations of patients with AD (Janson et al. 2004). In the current study therefore, alterations in metal homeostasis detected in participants with $\mathrm{AD}$ were not due to possible T2D.

While plasma levels of individual metals are of limited informational value here, how these metals are differentially co-regulated may represent a more useful measurement for further investigation as potential diagnostic biomarker of AD status. Likewise, other groups have indicated correlation coefficient matrix-assessed correlations as a suitable method to enable biomarker discovery in CNS-associated disorders (Nahan et al. 2017). Indeed, correlation analyses may assist in unmasking global dysregulation of systemic metal homeostasis in $\mathrm{AD}$ in a more

Table 3 Number of correlations for each group

\begin{tabular}{llll}
\hline${\text { Gender } \text { group }^{\text {a }}}$ & Strong correlations controls & Strong correlations AD & Shared correlations controls/AD \\
\hline Female (F) & $2(7.1 \%)$ & $0(0 \%)$ & $0(0 \%)$ \\
Male (M) & $1(3.6 \%)$ & $7(25.0 \%)$ & $0(0 \%)$ \\
Combined (F \& M) & $2(7.1 \%)$ & $7(25.0 \%)$ & $2(7.1 \%)$ \\
\hline
\end{tabular}

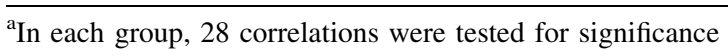


comprehensive way as many of the pathways where metals play distinctive roles are mutually interconnected. As just one example, $\mathrm{Cu}$ plays a major role in the regulation of systemic uptake and distribution of Fe (Nittis and Gitlin 2002). Therefore, we suggest that larger scale studies are needed to verify the alteration of plasma metal levels in $\mathrm{AD}$ and we indicate the monitoring of co-regulated plasma metals as a relevant measurement to be tested as potential diagnostic biomarker in $\mathrm{AD}$.

Finally, our results have significance for guiding future investigations on the utility of plasma metals as potential peripheral biomarkers to track rapidly progression or severity in subjects with $\mathrm{AD}$, and possibly to predict disease onset before clinical and neurological symptoms are clearly manifested. In addition, plasma metals might be relevant as pharmacodynamic/pharmacokinetic biomarkers to facilitate clinical studies involving metal chelation treatment in AD.

Acknowledgements We thank Cynthia Tse, University of Auckland, for reviewing the manuscript. This study was funded by The University of Manchester, the Central Manchester University Hospitals NHS Foundation Trust, the Northwest Regional Development Agency, by project grants from the Medical Research Council (MR/L010445/1) and Biotechnology and Biological Sciences Research Council (BB/I018654/1), and was facilitated by the Manchester Biomedical Research Centre and the Greater Manchester Comprehensive Local Research Network. GJSC also receives research funding and support from Endocore Research Associates (60187; 3601607); the Maurice and Phyllis Paykel Trust; Lottery Health (New Zealand); the Health Research Council (New Zealand); and a programme grant from the Ministry for Business, Innovation, and Employment (New Zealand; UOAX9902; PMIX0201; UOAX0705; UOAX0815). All data are provided in full in the results section of this manuscript.

\section{Compliance with ethical standards}

Conflict of interest GJSC is named as inventor on patents disclosing $\mathrm{Cu}$-selective chelators for the treatment of the diabetic complications and related diseases: these patents have been licensed and he has no financial interest in this work and declares no other duality of interest. All the other authors declare that they have no duality of interest with respect to this manuscript.

Open Access This article is distributed under the terms of the Creative Commons Attribution 4.0 International License (http:// creativecommons.org/licenses/by/4.0/), which permits unrestricted use, distribution, and reproduction in any medium, provided you give appropriate credit to the original author(s) and the source, provide a link to the Creative Commons license, and indicate if changes were made.

\section{References}

Adlard PA, Bush AI (2006) Metals and Alzheimer's disease. J Alzheimer's Dis 10:145-163

Akatsu $\mathrm{H}$ et al (2012) Transition metal abnormalities in progressive dementias. Biometals 25:337-350. https://doi.org/ 10.1007/s10534-011-9504-8

Ayton S, Lei P, Bush AI (2013) Metallostasis in Alzheimer's disease. Free Radic. Biol. Med 62:76-89. https://doi.org/ 10.1016/j.freeradbiomed.2012.10.558

Bush AI (2013) The metal theory of Alzheimer's disease. J Alzheimer's Dis 33:S277-281. https://doi.org/10.3233/ jad-2012-129011

Church SJ et al (2015) Deficient copper concentrations in drieddefatted hepatic tissue from ob/ob mice: a potential model for study of defective copper regulation in metabolic liver disease. Biochem Biophys Res Commun 460:549-554. https://doi.org/10.1016/j.bbrc.2015.03.067

Citron M (2010) Alzheimer's disease: strategies for disease modification. Nat Rev Drug Discov 9:387-398. https://doi. org/10.1038/nrd2896

Cooper GJS et al (2005) Demonstration of a hyperglycemiadriven pathogenic abnormality of copper homeostasis in diabetes and its reversibility by selective chelation. Diabetes 54:1468-1476. https://doi.org/10.2337/diabetes.54. 5.1468

Craddock TJ, Tuszynski JA, Chopra D, Casey N, Goldstein LE, Hameroff SR, Tanzi RE (2012) The zinc dyshomeostasis hypothesis of Alzheimer's disease. PLoS ONE 7:e33552. https://doi.org/10.1371/journal.pone.0033552

Ferri CP et al (2005) Global prevalence of dementia: a Delphi consensus study. Lancet 366:2112-2117

Fiandaca MS, Mapstone ME, Cheema AK, Federoff HJ (2014) The critical need for defining preclinical biomarkers in Alzheimer's disease. Alzheimer's Dement 10:S196-212. https://doi.org/10.1016/j.jalz.2014.04.015

Gerhardsson L, Lundh T, Minthon L, Londos E (2008) Metal concentrations in plasma and cerebrospinal fluid in patients with Alzheimer's disease. Dement Geriatr Cogn Disord 25:508-515. https://doi.org/10.1159/000129365

Huang X et al (1999) The A beta peptide of Alzheimer's disease directly produces hydrogen peroxide through metal ion reduction. Biochemistry 38:7609-7616. https://doi.org/10. 1021/bi990438f

Huang X, Moir RD, Tanzi RE, Bush AI, Rogers JT (2004) Redox-active metals, oxidative stress, and Alzheimer's disease pathology. Ann NY Acad Sci 1012:153-163

Huang CW, Wang SJ, Wu SJ, Yang CC, Huang MW, Lin CH, Cheng IH (2013) Potential blood biomarker for disease severity in the Taiwanese population with Alzheimer's disease. Am J Alzheimer's Dis Other Dement 28:75-83. https://doi.org/10.1177/1533317512467674

Janson J, Laedtke T, Parisi JE, O'Brien P, Petersen RC, Butler PC (2004) Increased risk of type 2 diabetes in Alzheimer disease. Diabetes 53:474-481. https://doi.org/10.2337/ diabetes.53.2.474

Kaddurah-Daouk R et al. (2013) Alterations in metabolic pathways and networks in Alzheimer/'s disease, Transl Psychiatry 3:e244. http://www.nature.com/tp/journal/v3/ n4/suppinfo/tp201318s1.html 
Lovell MA, Robertson JD, Teesdale WJ, Campbell JL, Markesbery WR (1998) Copper, iron and zinc in Alzheimer's disease senile plaques. J Neurol Sci 158:47-52

McKhann G, Drachman D, Folstein M, Katzman R, Price D, Stadlan EM (1984) Clinical diagnosis of Alzheimer's disease: report of the NINCDS-ADRDA Work Group under the auspices of department of health and human services task force on Alzheimer's disease. Neurology 34:939-944

Miller LM, Wang Q, Telivala TP, Smith RJ, Lanzirotti A, Miklossy J (2006) Synchrotron-based infrared and X-ray imaging shows focalized accumulation of $\mathrm{Cu}$ and $\mathrm{Zn}$ colocalized with beta-amyloid deposits in Alzheimer's disease. J Struct Biol 155:30-37. https://doi.org/10.1016/j.jsb. 2005.09.004

Nahan KS, Walsh KB, Adeoye O, Landero-Figueroa JA (2017) The metal and metalloprotein profile of human plasma as biomarkers for stroke diagnosis. J Trace Elem Med Biol 42:81-91. https://doi.org/10.1016/j.jtemb.2017.04.004

Nittis T, Gitlin JD (2002) The copper-iron connection: hereditary aceruloplasminemia. Semin Hematol 39:282-289

Prince M, Guerchet M, Prina M (2013) Policy brief for heads of government: the global impact of dementia 2013-2050. Alzheimer's Dis Int 2013:1-8

Ramos P, Santos A, Pinto NR, Mendes R, Magalhaes T, Almeida A (2014) Anatomical region differences and agerelated changes in copper, zinc, and manganese levels in the human brain. Biol Trace Elem Res 161:190-201. https://doi.org/10.1007/s12011-014-0093-6

Roberts BR, Ryan TM, Bush AI, Masters CL, Duce JA (2012) The role of metallobiology and amyloid-beta peptides in
Alzheimer's disease. J Neurochem 120:149-166. https:// doi.org/10.1111/j.1471-4159.2011.07500.x

Sastre M, Ritchie CW, Hajji N (2015) Metal ions in alzheimer's disease brain. JSM Alzheimer's Dis Relat Dement 2:1014

Schrag M et al (2011) Effect of cerebral amyloid angiopathy on brain iron, copper, and zinc in Alzheimer's disease. J Alzheimer's Dis 24:137-149. https://doi.org/10.3233/ jad-2010-101503

Smith DG, Cappai R, Barnham KJ (2007) The redox chemistry of the Alzheimer's disease amyloid beta peptide. Biochem Biophys Acta 1768:1976-1990. https://doi.org/10.1016/j. bbamem.2007.02.002

Squitti R (2012) Metals in alzheimer's disease: a systemic perspective. Front Biosci 17(1):451

Vardy ER, Rice PJ, Bowie PC, Holmes JD, Grant PJ, Hooper NM (2007) Increased circulating insulin-like growth factor-1 in late-onset Alzheimer's disease. J Alzheimers Dis 12:285-290

Vardy ER, Rice PJ, Bowie PC, Holmes JD, Catto AJ, Hooper NM (2009) Plasma angiotensin-converting enzyme in Alzheimer's disease. J Alzheimers Dis 16:609-618

Vural H, Demirin H, Kara Y, Eren I, Delibas N (2010) Alterations of plasma magnesium, copper, zinc, iron and selenium concentrations and some related erythrocyte antioxidant enzyme activities in patients with Alzheimer's disease. J Trace Elem Med Biol 24:169-173. https://doi. org/10.1016/j.jtemb.2010.02.002

$\mathrm{Xu} \mathrm{J}$ et al (2017) Evidence for widespread, severe brain copper deficiency in Alzheimer's dementia. Metallomics 9:1106-1119. https://doi.org/10.1039/c7mt00074j 